This item was submitted to Loughborough's Research Repository by the author.

Items in Figshare are protected by copyright, with all rights reserved, unless otherwise indicated.

\title{
Overcoming fears: a pathway to publishing for early career researchers
}

PLEASE CITE THE PUBLISHED VERSION

https://doi.org/10.1108/DPM-07-2019-0197

PUBLISHER

Emerald Publishing Limited

VERSION

AM (Accepted Manuscript)

LICENCE

CC BY-NC 4.0

REPOSITORY RECORD

Drosou, Nafsika, Monia Del-Pinto, Mohammed Al-Shuwaili, Susie Goodall, and Elisabeth Marlow. 2019. "Overcoming Fears: A Pathway to Publishing for Early Career Researchers". Loughborough University. https://hdl.handle.net/2134/9971636.v1. 


\section{OVERCOMING FEARS: A PATHWAY TO PUBLISHING FOR EARLY CAREER RESEARCHERS}

\section{Abstract \\ Purpose}

This paper presents reflections of five early career researchers on the challenges of journal publishing and how to tackle them.

Design

The authors attended a participatory workshop on demystifying academic publications. Working individually and in groups they shared, discussed, analysed, visualised and ranked perceived challenges and opportunities concerning academic publishing. They then delved in the existing literature on the subject. Following their enhanced understanding of the area they reflected on the experience and learnings.

\section{Findings}

Personal confidence relating to the development of a scholarly identity was found to be a critical factor in the attitude toward journal publishing. Supervisory and peer support, accessibility to journal editors, as well as opportunities to reflect on the writing, publishing and peer review processes through participatory workshops and writing groups, were deemed more effective than formal and conventional guidance schemes.

\section{Research implications}

This work adds to the available literature regarding the issue of academic publishing for PhD students and early career researchers.

\section{Practical implications}

The work presented here addresses the issue of journal publishing from the perspective of persons who directly experience this apprehension as PhD students and co-authors of this and other papers. Shedding light on these issues allows the realisation that they are common among early career researchers and leads a step closer to resolving them.

\section{Originality}

The paper contributes to a deeper understanding of issues surrounding publishing apprehension, by laying out thoughts that are seldom expressed.

\section{Keywords}

Journal publishing, academic writing, early career researchers (ECR), fear, selfefficacy

\section{Introduction}

Publishing academic outputs is both an essential requirement for an academic career, and an integral part of the research process as ideas are refined through the 
peer-review process and knowledge is shared and exchanged. Clapham (2005, p.390) asserts that "publications are the scientific method", in that published knowledge is shared with the academic community and leads to the development of new paradigms and the acceptance, modification or rebuttal of hypotheses. Lee (2014) critiques the prevalent 'publish-or-perish' status quo, noting the anxiety it causes among early career and established researchers, and proposing a new definition of "scholarliness" based on knowledge dissemination. Early career researchers, in particular, face additional challenges in writing and publishing, including fear (Sommers and Saltz 2004; Li 2008), the need to develop one's own voice (Cotterall 2011) (especially where the author's first language is not English (Cho 2009; Gea-Valor et al. 2014)), fluctuating self-belief, poor engagement with peers, the lack of support networks and organisational and technical difficulties (Gopee and Deane 2013). Despite resources being available for helping early career researchers navigate the peer review process and improve their academic writing skills, here we find that participatory workshops, with direct inputs from an academic journal editor, are one effective way of helping them identify and overcome these challenges.

This paper is written by research students and early career researchers who attended a participatory workshop titled "Demystifying Academic Publications: A Writeshop For The PhD And Post-Doctoral Researchers Working In The Area Of Disaster Risk Reduction And Resilience", held at Loughborough University in January 2019. The authors can relate to the anxiety associated with publishing journal papers, as well as the struggles and perceived barriers encountered by early career researchers in their effort to break into the academic world. The terms 'early career', 'novice' and 'post-doctoral researchers' as well as 'research', 'postgraduate' and 'PhD students' are used interchangeably throughout this work, as they all are novice academic journal paper authors.

The following sections include a review of the literature concerning the area of journal publishing for early career researchers (noting that the authors were not aware of it before the workshop), the workshop experience, and results involving publishing challenges and opportunities that surfaced. The discussion examines how the challenges and opportunities align with those established in the literature, and shares the practical insights we gained for the benefit of other PhD and post-doctoral researchers. 


\section{Getting on the publishing ladder}

\subsection{The peer review process}

According to the Publishing Research Consortium Peer review survey 2015 (Ware 2016), peer review is the process by which researchers' reports of scientific and other scholarly advances are reviewed prior to (or in some cases, following) publication in research journals. It is a matter of importance not just to researchers and journal publishers, but also to research funders, policymakers, and indeed the general public.

In the UK the peer review process dates back to 1731. However, it was in the 1950s that it started to be seen as pivotal to scholarly dissemination and an essential element that supports confidence in scientific research. Over 1.5 million scholarly articles are published each year under the peer review process (Wilson 2012). A significant percentage of scholarly articles submitted are rejected either during this process or even before that. Taking Elsevier, as an example, the number of rejected papers is 30 to 50 per cent (Thrower 2012). Figure 1 illustrates the peer review stages.

Journal publications commonly adopt three types of peer review process: (i) single blind, in which the reviewers' names are not communicated to the authors; (ii) double blind, wherein the reviewers' and authors' names are not revealed to each other; (iii) open peer review, wherein both reviewers' and authors' identities are known. In most cases two experts are required for reviewing, nevertheless this number can increase in accordance with the specific journal policy.

Peer reviewed journals are typically associated with credibility in academia, and dissemination in such journals is important to the progress in a researchers' career (De Rond and Miller, 2005). Furthermore, funding opportunities are strongly related to research and impact. This process is also a prerequisite for the integration of new research findings in academia, industry and knowledge in general. In addition, it significantly reduces plagiarism attempts. Thus, the ability to present academic work in the format of a journal paper that satisfies the requirements of such a rigorous process is an essential skill for all academics, making the peer review a challenging task for many authors in the early stages of their research career. 


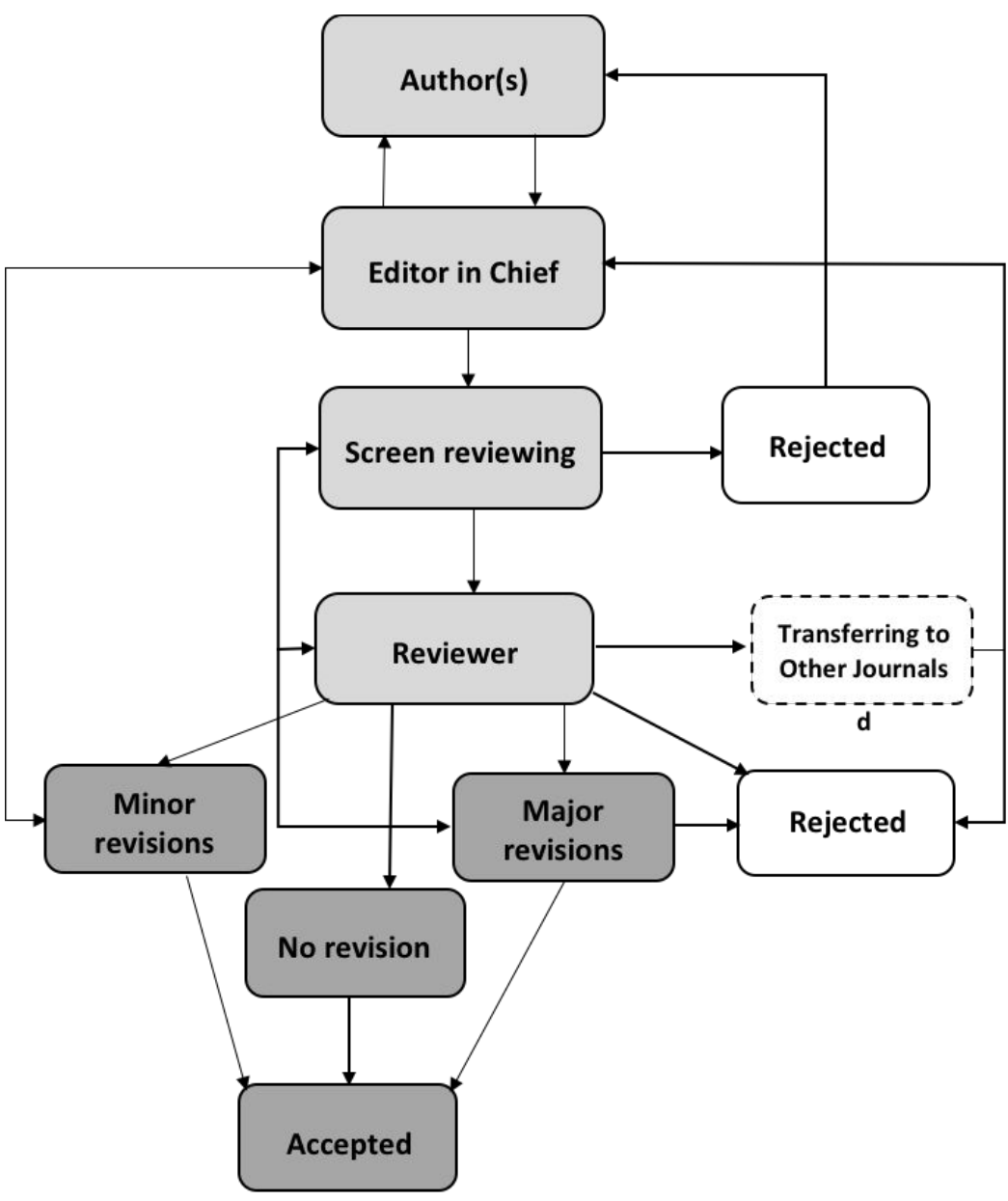

Figure 1: The typical peer review process for academic journals.

\subsection{Publication challenges for novice journal paper authors}

Despite $91 \%$ of researchers thinking that their work has been improved by the reviewer remarks, one of the most frequent, and often overlooked, issues today is the apprehension or fear of young researchers to write a peer-reviewed article (Vintzileos and Ananth 2010). The basis of this fear is often attributed to the disagreement between the authoritative stance journal authors are expected to adopt in their respective fields and the fact that "doctoral writers are likely to consider themselves relative newcomers to the field" (Sommers and Saltz 2004, p.133, in Cotteral 2011). This dissonance is amplified by the expectation that scholarly authors "develop their own 'voice' (Belcher and Hirvela 2001) and infuse their writing with a sense of personal identity (Ivanic 1998)" (Cotteral 2011, p. 414).

Finding one's own 'voice' and the fear of sounding simplistic are even more challenging for authors whose first language is other than English. A study 
concerning engineering students and faculty members in Korea finds that about $92 \%$ and one-third of respondents respectively, felt disadvantaged publishing their papers in English journals. Perceived disadvantages included the additional time it takes to write and correct papers in English, as well as the psychological pressure related to writing in a non-native language (Cho 2009). The same study identifies "overall paper organization and paragraph development" (Cho 2009, p.237) as more important than linguistic features, of which the most difficult element is found to be sentence structure.

Fluctuating self-belief is a barrier identified by Gopee and Deane (2013). The lack of confidence in the academic aspect of research students' work is a barrier also noted in the study of Timmons and Park (2008). Having the very first paper harshly rejected could add all the more to their lack of confidence. Obuku et al. (2018) also find that confidence is a reason for low research productivity in low-middle income countries, as is the lack of use of postgraduate research in informing policy, along with poor supervision.

The important role of the supervisors, regardless of whether they are from academia or industry, also extends to their contribution concerning the development of the novice scholarly author they supervise. In this regard Gopee and Deane (2013) revealed the postgraduate students' "fear of approaching subject tutors for help and further explanation, in case they are made to feel foolish by tutors". An example of the qualitative data they collected refers to the quote "I didn't get as much help as I had thought. ... I ended up bit more confused ... on that particular question" [p.1627]; this occurs regularly among doctoral students. Another element of the studentsupervisor relationship that could pose a challenge to publishing is the student not willing to depend on the supervisor, and the reluctance to ask for feedback or to challenge the supervisor's contribution. In cases where the student works in isolation, the student-supervisor relationship becomes more critical in the development of the student's perception as a scholarly author. Gopee and Deane (2013) present poor engagement with peers and the lack of support networks as challenges to journal writing too.

Further obstacles that doctoral students face involve organisational and technical difficulties, such as "problems with word choice, and achieving academic coherence, adhering to the word limit, assignment submission cut-off dates, and being sufficiently organised to do so" (Gopee \& Deane, 2013, p. 1627). Cotterall (2011) 
notes the particular challenge students face in starting a paper or writing the introduction. Often this may lead to writers' block hindering the transfer of the students' ideas on to paper.

Another challenge that is magnified in the case of international students and students with learning disabilities, concerns the uncertainty about academic writing conventions and efforts to avoid plagiarism as a challenge (Gopee and Deane 2013). A separate technical difficulty is presented by Timmons and Park (2008) and involves research students being put off by constraints that involve the presentation of ethical approval.

Several authors have looked at the progression of academic careers, going from postgraduate (doctoral) researcher through to an early career researcher, and onwards to tenured faculty positions. Developing research skills, and producing research outputs are argued to be the most challenging aspects for early career researchers (Hemmings 2012), and also critical for doctoral researchers.

\subsection{Overcoming the challenges}

Advice on how to publish abounds and stems from many different fields (Skelton 1994; Choi 2002; Johnson 2008; Jalalian et al. 2012; Derntl 2014; Light 2015). Yet many aspects of the publishing process still seem opaque (Cormode 2013). It is not necessarily a lack of knowledge or advice that makes the progression from 'dependent' to 'independent researcher' challenging (Laudel and Gläser 2008). Research by Hemmings and Kay (2010) identifies the concept of "self-efficacy" as the crucial difference between early career researchers who publish their research and those who do not. Self-efficacy is related to confidence and is described as comprising: research conducting, managing, reporting and supervising; major works (articles/books) writing and reviewing; and attaining a broad view of a research area. How then can early career researchers overcome journal writing and publishing challenges they face? Proposed solutions include writing courses and writer support groups (Rickard et al. 2009), institutional and non-institutional peer support (Gopee \& Deane 2013) and improving pedagogy (Cotterall 2011) - although these may neither be accessible nor relevant for all. We now share our experience of a participatory approach for engaging with publishers and editors. 


\section{Methodology}

The workshop held at Loughborough University on 27 January 2019 presented an opportunity for PhD students and early career researchers to develop writing skills and demystify the journal publishing process. It was facilitated by a publisher representative, a journal editor and a lecturer (who's also a member of the journal editorial board). A total of six participants with a range of backgrounds that included structural engineering, inventory management/logistics, architecture, building energy and water/earth sciences, connected under the theme of resilience and disaster risk reduction. Two of the participants were native English speakers. The participants were guided through a series of targeted activities designed to shed light on the publication process. Along with the expected outcomes, i.e. develop writing skills and awareness of publishing mechanisms, the dialectic character of the workshop sessions provided an additional outcome, enabling the identification of barriers and positive prospects related to journal publishing.

The workshop was constructed by posing questions at individual, small group and collective levels as follows:

- Participants individually formulated a set of questions on writing and publishing journal papers. The questions were collectively discussed and the five most prominent were chosen. Questions included: "Can we respond to the reviewer?"; "How do we make our point?"; "How do we write a good paper and minimise the chance of rejection?" among others;

- In small groups and with constricted time the participants discussed and noted answers to the five questions on flip charts;

- A facilitated round table discussion then took place stemming from the answers provided by each small group. The format was unstructured and flexible question and answer that allowed participants to share personal concerns and experiences relating to academic publishing;

- Participants individually summed up the outcomes using single-word definitions and identified challenges (i.e. perceived barriers) and opportunities (i.e. pathways) that emerged;

- The results were collected, displayed and ranked enabling mapping out the challenges and opportunities. Figure 2 provides a visual of the mapping process, although the contents are analytically presented in the next section. 
(a) Ranking challenges

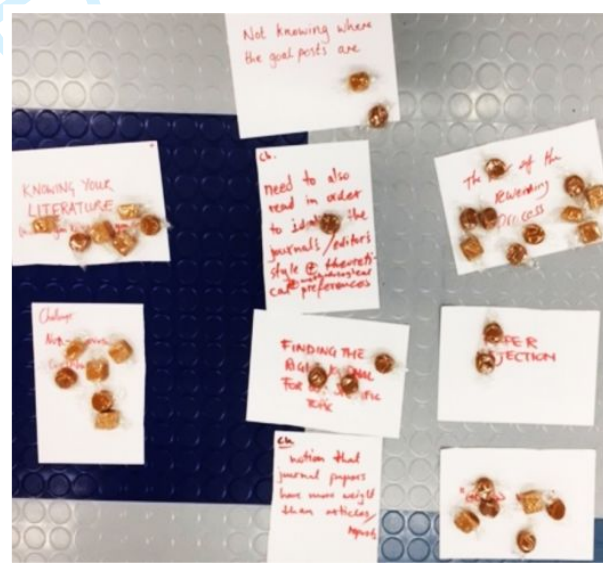

(b) Ranking opportunities

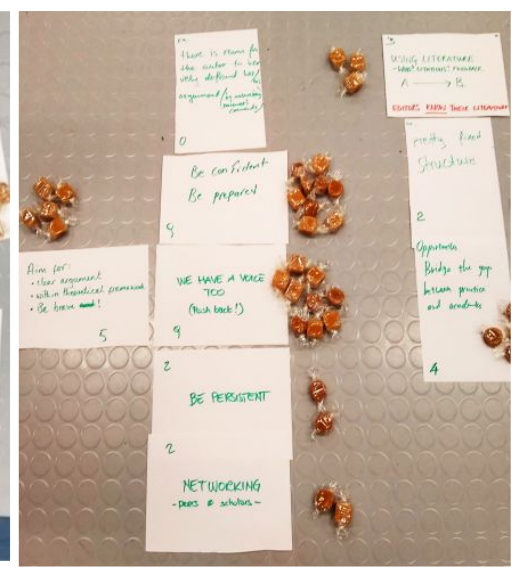

(c) Creating links

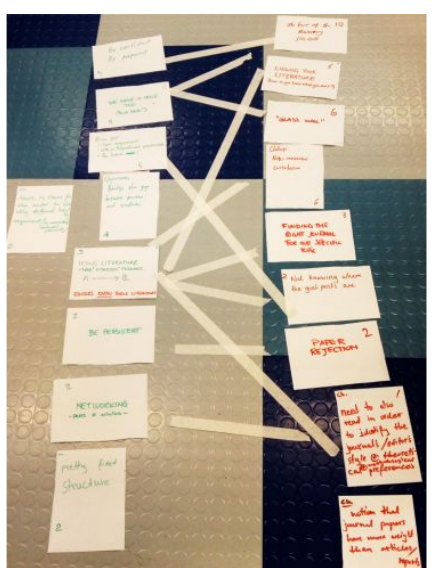

Figure 2: Workshop images of ranking and linking challenges and opportunities to publishing

Through this participatory process, the participants unknowingly identified underlying barriers and opportunities, deconstructed and voiced their fears and feelings. The round table discussion was the key moment when the participants' comments, complemented by the editor's and publisher's feedback, enabled the identification and analysis of the perceived barriers to publishing and revealed the counterbalancing positive aspects. The result was the gradual elucidation of underlying fears and available resources, as well as the map of pathways to successfully approach academic publishing. The overall outcome was geared toward finding a 'voice' and sharing the workshop process with others in a similar position. The process itself was found to be a very useful support tool on how to produce journal papers, including the encouragement to put what had been discussed into practice by co-authoring an academic journal paper as a team. The following section describes how the results from the workshop (both written outputs and changes in perceptions of the participants) were then analysed and presented.

\section{Workshop results}

The identification of challenges and opportunities for early career publishing was the final and core segment of the workshop. It can be viewed as a presentation of participant feelings vs. actions (i.e. concerns vs. pathways), representing to some extent their attitude toward publishing, before and after the workshop's activities. 
Figures $3 \& 4$ present the results, classified by themes of self-confidence, knowledge and communication.

\subsection{Challenges}

The challenges that emerged during the round table discussion involve perceived barriers to the publication process and embody the main fears preventing novice researchers from being proactive authors and submitting scientific articles. The challenges, summarised in Figure 3 , trace their routes to "fear", based on a widespread lack of self-confidence that is reinforced by a perceived lack of both information about the publication process and communication channels with editors or publishers.

The ranking exercise showed the following trends:

- The primary challenge novice journal authors face is associated with fear related to the writing and rewriting process (including initial drafting and rewriting following feedback and comments from supervisors and reviewers), scoring 10 points on the overall rating;

- Other barriers follow, relating to uncertainties regarding the relevant literature (8 pts), the perception of a "glass wall" between the domains of research and publishing, as well as the concern of presenting a non-innovative contribution (6 pts);

- Minor challenges are finding a journal that suits the expected research goals (3pts), dealing with rejection and facing unknown goalposts (2pts). The effort to identify the editors' theoretical and methodological preferences scored 1 point.

The reference to fear underlies, more or less explicitly, all the points that appeared in the discussion and is in line with contributions from literature highlighting the contrast between the authors' self-expectations (i.e. being authoritative) and their selfreliance (i.e. newcomers to the field, still building their own voice) (Sommers and Saltz 2004; Li 2008). Other concerns related to knowledge gaps and the risk of involuntary plagiarism, as well as additional insecurities potentially fostered by language barriers of authors who's native language is not English and who are not exposed to Anglophone academic writing style within a prevalently Anglophone publishing context (Cho, 2009). International participants of the round table discussion also touched on the subject of cultural differences in organising and 
presenting scholarly work. These differences are also apparent among different disciplines and perhaps less so among different journals.

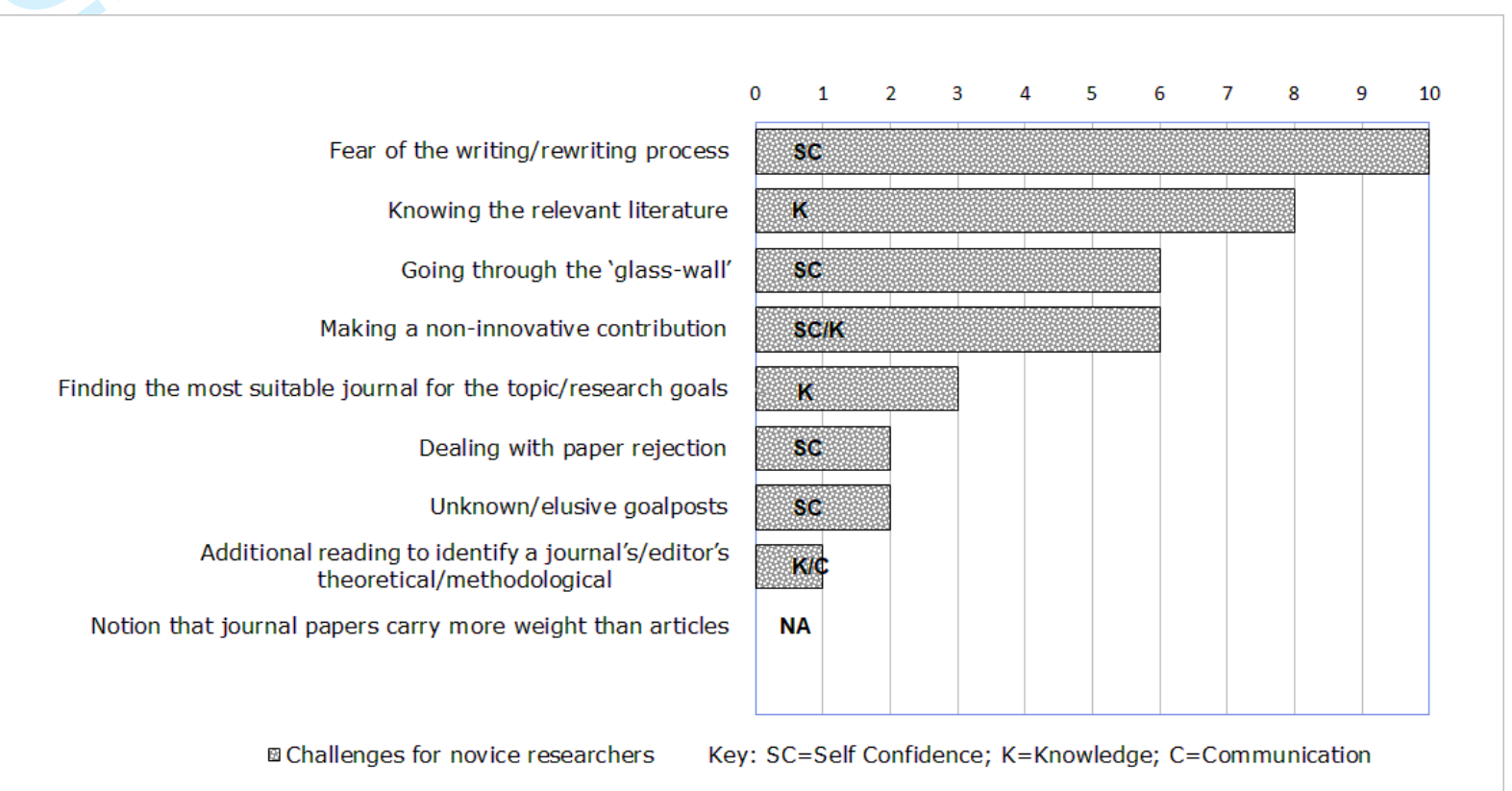

Figure 3: Ranking of perceived challenges novice journal authors face

The resulting fluctuation in self-belief, discussed in the workshop and pointed out in the literature (Gopee and Deane 2013), tends to reinforce misconceptions regarding how approachable the editors are and whether paper rejections are irrevocable or not. All of these factors coerce to discourage the novice author from publishing or result in delays and procrastination of paper submissions.

\subsection{Opportunities}

Opportunities represented both lessons learned during the discussion (i.e. tips to positively engage the process of publishing and to bear in mind to overcome the challenges) and the perceived positive aspects of publishing. Similar to the challenges, these are summarised and ranked in a Figure 4 revealing the main trends and possible patterns.

The rating provides an outline of the main trends within the group:

- Preparation and confidence are perceived as the main opportunity (rated 9pts). Early career researchers consider themselves prepared and consequently confident about their submission after completing the literature familiarisation and research design groundwork, and then conducting their 
research. The two factors are linked to 'having a voice too' and the awareness of being entitled to respond to a reviewer (since there is room for the author to defend an argument).

- More pragmatic aspects follow, such as aiming for a clear argument rooted in a solid theoretical framework (5pts) and underpinned by suitable literature (3pts), as well as bridging the gap between academia and publishers/editors (4pts).

- Networking and persistence, as well as a fixed structure for the paper, are perceived as an additional but not primary opportunity (2pts).

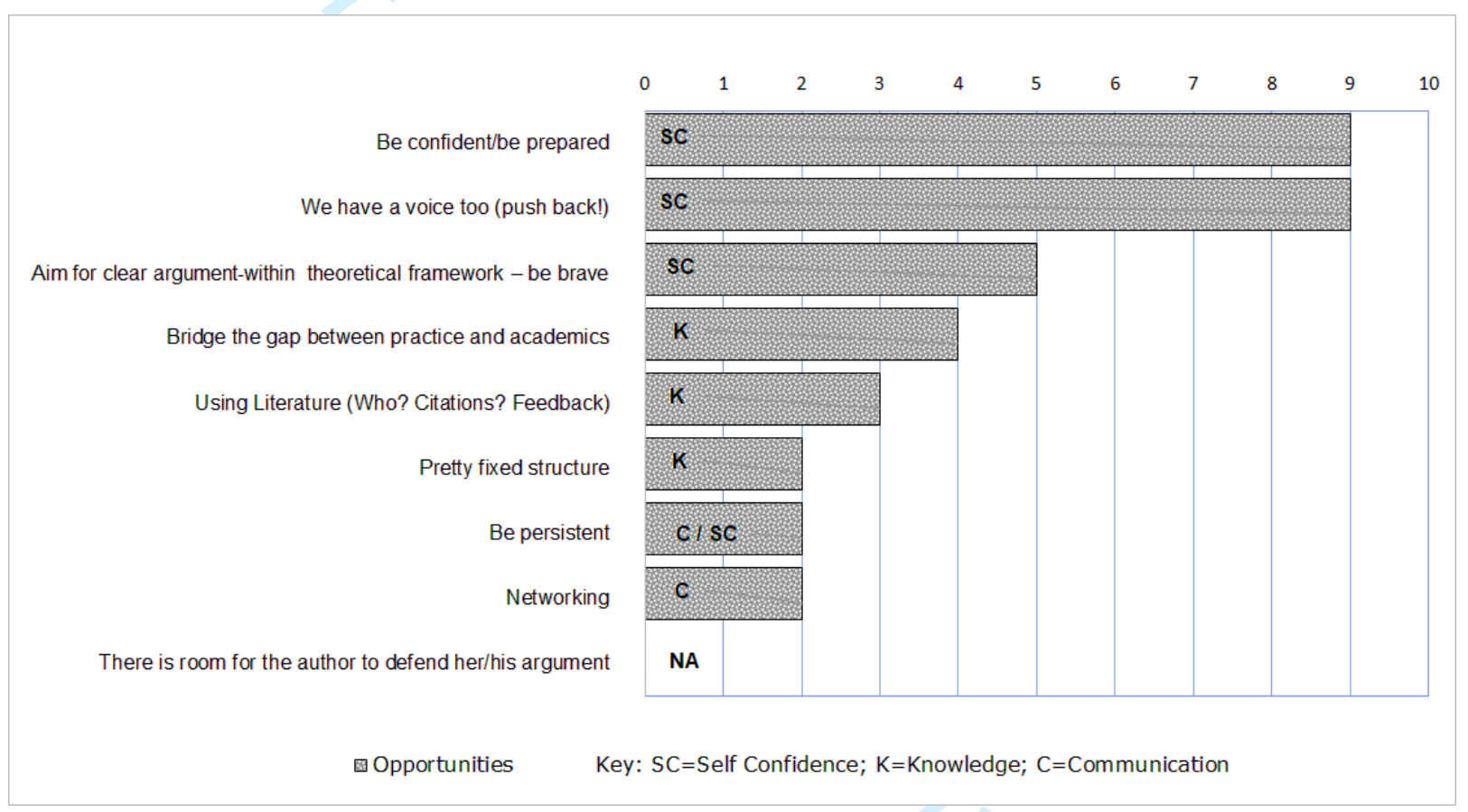

Figure 4: Ranking of publishing advice and benefits for novice journal authors Data in Figure 4 are in line with the outcomes of existing qualitative studies (e.g. Hemmings, 2012): self-perception and confidence, along with reliance on one's research skills, have the leading role in early career researchers' publication records. Here both confidence and preparation stand out as personal skills that enable the early career researcher to make the first steps into the "unexplored" dimension of publishing. The discussion between the editor and the participants also suggests that a reflective process could enhance awareness and strengthen selfefficacy, which are positive characteristics that counteract doubts and are key features of a successful researcher. 


\section{Discussion}

Mapping out the challenges and opportunities enabled the identification of links between perceived barriers and counteracting strategies, as well as grouping them into three main "thematic blocks": self-reliance, knowledge, and communication (Figure 5).

The most prominent challenges that surfaced in the discussion fall under the theme of self-reliance. In line with trends expressed in literature, a fluctuating self-belief is the main barrier which underlies "dealing with paper rejection" (Gopee and Deane 2013) and prevents authors from responding to reviewers frankly (as opposed to trying to address every single comment), even when this is a standard practice in journal paper publishing. Thus it is not surprising that workshop participants choose to word one of the challenges they face as going through the "glass wall". The workshop outcomes showed that counterbalancing actions become possible when the novice authors are aware of the mechanisms behind the publishing process. Understanding the impact of the reviewers' background on feedback they provide and becoming conscious of the editor's weight on the final decision reinforces the inexperienced authors' confidence; places a potential paper rejection into perspective and encourages perseverance.

Regarding the knowledge theme, the general insecurity surrounding the presentation of the literature is a perceived barrier referred to by participants as "how do you know what you don't know?" Perceiving goalposts in literature reporting and research presentation as elusive, adds insecurity and stress in deciding what to include/exclude and what renders meanings too dense or too simplistic. The amount of additional reading and research focused on understanding the acceptable standards and conventions of each journal is a task necessary for enhancing the success of the submission but is an additional challenge in terms of time and effort. In close proximity to this challenge is that of selecting the roster of best suited journals for the topic and the specific goals the paper serves. Added to this is the pressure to publish in high rank journals that may not always be the most suitable. Even when a complete draft has been produced, it is accompanied by multiple doubts concerning contribution to knowledge and whether the work is innovative. 
Concerning the communication theme, it is interesting that results of this study agreed not only with findings of similar studies concerning international authors (Cho 2004), but also with "previous research carried out in a first language setting (Shaw 1991; Casanave and Hubbard 1992; Jenkins et al. 1993; Dong 1998)" (Cho, 2009, p. 237 ) showing that the use of academic language poses a crosscutting challenge. Using a language other than one's own compounds the fear associated with challenging established or introducing new knowledge. Perhaps shifting the focus onto the challenge posed by language handling, which is a tactile technical issue with rules, is a means to tackle the emotionally charged, abstract and difficult to deal with fears surrounding self-confidence.

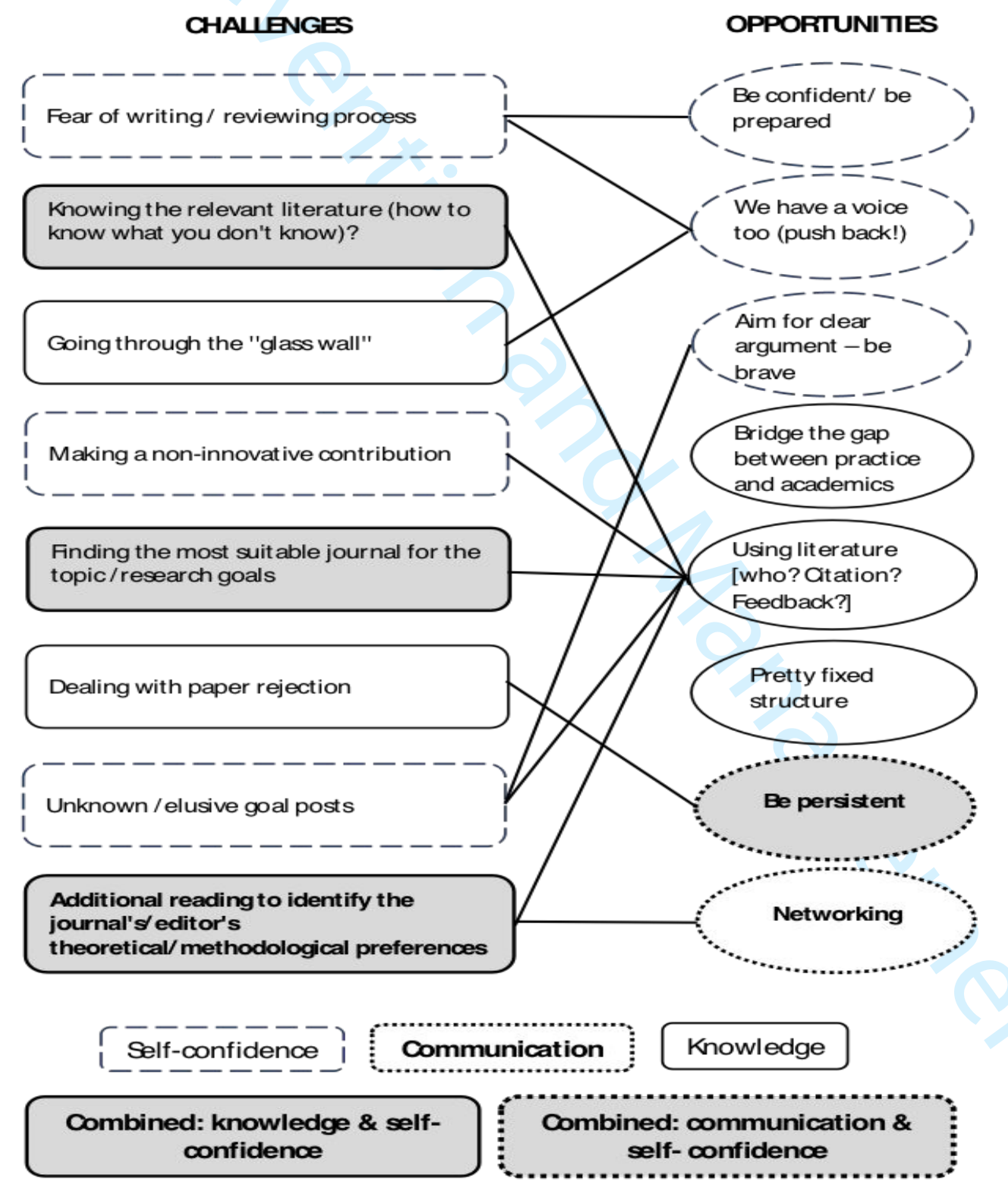

Figure 5: Linking publishing challenges to opportunities and grouping them into three thematic blocks. 
The hindering aspects related to each theme were characterised by a negative connotation in the challenges column but found a positive counterpart in the list of opportunities (Figure 5). The negative impact of some common concerns related to early career publishing can be counterbalanced by an improved understanding of the review process, guidance on how to write a piece of work suitable for publishing, and the progressive development of self-reliance skills throughout a researcher's career. As a final section of the discussion, we share the individual participants' reflections on how the workshop and co-authoring process has changed our perceptions and practices in publishing as early career researchers.

'I've had opportunities to write papers in the past, for example my Masters' thesis, but lacked the confidence and know-how to do it. I can really identify with the challenge of 'finding one's own voice' described in the literature, which can cripple the first attempts to put your research out into the published world. Discussing this with other early career researchers, and hearing from established academics that publishing is also still a challenge for them gave a sense of solidarity, and shifted my focus from my own self-doubt to finding opportunities and solutions. Before it felt like there was a huge barrier in the way of publishing a paper - a compound mix of not knowing what was expected and a lack of confidence that I could meet those unknown expectations. Discovering what the barriers are is the first step to overcoming them, and going on from the workshop to write this paper with some fantastic colleagues has been empowering." (Participant A)

“The workshop was an 'initiator' to understand and discuss as a collective group what it takes to make a publication. The commitment to writing a paper helped consolidate the workshop learnings to overcome our fear ( $\mathrm{l}$ think through a joint responsibility) and personally, I also felt a sense of detachment because it wasn't 'my' research, it was shared work which changed my emotional context and I could contribute freely." (Participant B)

"The workshop was a rare chance to meet an Editor in Chief, a publisher, an academic and early carrier researchers at the same time in an open discussion trying to explore the publishing world [...] I think the workshop has increased not only our knowledge about publishing but also our self-confidence in dealing with this process. The reviewing process is affected significantly by human reflection rather than the systematic and rigorous approach to evaluate the author's contribution. The authors spend a lot of time and effort on writing their paper. Although I appreciate 
that the work of the reviewers is generally free, I wish the reviewers could dedicate more time to review the work; it is often the case that the reviewing process occurs during waiting or [...] travelling time." (Participant C)

"The workshop made us, the participants, aware that elements we perceive as individual challenges are, more often, shared concerns: the initial effort we had to make, to identify and share what our thoughts and questions were, revealed to be an extremely useful exercise once all the thoughts had been mapped out. I found the discussion the key moment, since we productively shared the outcomes of our individual self-reflection, overcoming the fear of self-doubt and reinforcing our confidence thanks to the editor's will to listen to and interact with us. Furthermore, I found extremely useful elaborating on the workshop's outcomes and turning my individual experience into a contribution to inform early career researchers - not providing them with guidelines on how to write a good paper, but rather offering a perspective they can identify with." (Participant D)

"I found the workshop's communication intensive process vital in awakening a kind of confidence in my own academic abilities and my scholarly 'voice'; it worked a bit like a calibration and reassurance tool for me. Co-authoring this paper was a perfect opportunity to apply this new attitude. Before the workshop I thought that becoming conscious of my 'voice' and my potential to contribute to journal publications was a rather personal and internal process. However, the most beneficial thing has been listening about other researchers' experiences and interacting with them. This includes both the workshop participants (I realised that my issues are actually common issues among early career researchers) and the facilitators (journal editor, lecturer and publisher representative). Their approachable and supportive attitude changed the way I perceived the distance between us; I now see it as a matter of a few attainable steps and appreciate the helping hand they extended to us through the laid back, playful and participatory workshop activities. I hope this paper also works as a helping hand for other researchers at the start of their publishing journey." (Participant E)

\section{Conclusions}

The reflective process facilitated by the workshop's activities and the direct, informal interaction between researchers and editor, were key in identifying the relationship between challenges and opportunities, as opposed to formal and conventional 
guidance schemes. The dialogue with the editor, in particular, represented the core of "demystifying the publishing process" and reinforced the participating early career researchers' self-awareness.

Supervisory and peer support, as well as writing groups/gyms were deemed useful in overcoming publishing apprehension, as they provide much needed affirmation regarding technical aspects of language and build the scholarly 'writing muscle'.

The potentially negative impact of reviewers' feedback can be turned around from an apparent challenge into an opportunity for growth, when the interaction with the editor and reviewers reflects the overall value of the novice's work as much as the necessary revisions.

Discussing the challenges and opportunities through the workshop has shown that writing a paper is more relevant to personal confidence and publishing a paper to overcoming the 'fear' of the unknown with group support. Although achieving this is complicated, engaging in dialogue with the editors and publishers leads one in the right direction, since it reduces both what is considered unknown and the fear of the publishing process. Moreover, it leads to additional benefits as the publishers increase their involvement and their role in shaping the dissemination of knowledge through their publication. Thus, it is beneficial for publishers to outline their 'go-to' structure, work with academic institutions and be accessible to journal authors.

\section{Acknowledgement}

The authors gratefully acknowledge the Institute of Advanced Studies(IAS) at Loughborough University-UK for organising 'Demystifying academic publications: Writeshop' which led to this study, Prof J.C. Gaillard from University of Auckland-New Zealand for presenting the Writeshop, Dr Ksenia Chmutina for reviewing this paper and Emerald publication for supporting the event.

\section{References}

Belcher, D. and Hirvela, A. (2001), "Voice in L2 writing", Journal of Second Language Writing, Vol. 10 No. 1.

Casanave, C.P. and Hubbard, P. (1992), "The writing assignments and writing problems of doctoral students: Faculty perceptions, pedagogical issues, and needed research", English for Specific Purposes, Vol. 11 No. 1, pp. 33-49.

Cho, D.W. (2009), "Science journal paper writing in an EFL context: The case of 
Korea", English for Specific Purposes, The American University, Vol. 28 No. 4, pp. 230-239.

Cho, S. (2004), "Challenges of Entering Discourse Communities Through Publishing in English: Perspectives of Nonnative-Speaking Doctoral Students in the United States of America", Journal of Language, Identity, and Education, Vol. 3 No. 1, pp. 47-72.

Choi, K. (2002), How to Publish in Top Journals, Ames.

Clapham, P. (2005), "Publish or Perish", Bioscience, Vol. 55 No. 5, pp. 390-391.

Cormode, G. (2013), "What does an associate editor actually do?", ACM SIGMOD Record, Vol. 42 No. 1, p. 52.

Cotterall, S. (2011), “Doctoral students writing: Where's the pedagogy?", Teaching in Higher Education, Vol. 16 No. 4, pp. 413-425.

Derntl, M. (2014), "Basics of research paper writing and publishing", International Journal of Technology Enhanced Learning, Vol. 6 No. 2, p. 105.

Dong, Y.R. (1998), “Non-native graduate students' thesis/dissertation writing in science: Self-reports by students and their advisors from two U.S. institutions", English for Specific Purposes, Vol. 17 No. 4, pp. 369-390.

Gea-Valor, M.L., Rey-Rocha, J. and Moreno, A.I. (2014), "Publishing research in the international context: An analysis of Spanish scholars' academic writing needs in the social sciences", English for Specific Purposes, Elsevier Ltd, Vol. 36 No. 1, pp. 47-59.

Gopee, N. and Deane, M. (2013), "Strategies for successful academic writing Institutional and non-institutional support for students", Nurse Education Today, Elsevier Ltd, Vol. 33 No. 12, pp. 1624-1631.

Hemmings, B. (2012), "Sources of research confidence for early career academics: A qualitative study", Higher Education Research and Development, Vol. 31 No. 2, pp. 171-184.

Hemmings, B. and Kay, R. (2010), "Research self-efficacy, publication output, and early career development", International Journal of Educational Management, Vol. 24 No. 7, pp. 562-574.

Ivanic, R. (1998), Language and Identity: The Discoursal Construction of Identity in Academic Writing, John Benjamins Publishing Company, Amsterdam.

Jalalian, M., Aslam, H.D., In-chief, E. and Journal, E.P. (2012), "Writing for academic journals: A general approach. Electronic physician”, Electronic Physician, Vol. 4 
No. 2, pp. 474-476.

Jenkins, S., Jordan, M.K. and Weiland, P.O. (1993), "The role in writing of graduate engineering education: A survey of faculty beliefs and practices", English for Specific Purposes, Vol. 12 No. 1, pp. 51-67.

Johnson, T.M. (2008), "Tips on how to write a paper", Journal of the American Academy of Dermatology, American Academy of Dermatology, Inc., Vol. 59 No. 6, pp. 1064-1069.

Laudel, G. and Gläser, J. (2008), "From apprentice to colleague: The metamorphosis of Early Career Researchers", Higher Education, Vol. 55 No. 3, pp. 387-406.

Lee, I. (2014), "Publish or perish: The myth and reality of academic publishing", Language Teaching, Vol. 47 No. 2, pp. 250-261.

$\mathrm{Li}, \mathrm{X}$. (2008), "Learning to write a thesis with an argumentative edge", in Casanave, C.P. and Li, X. (Eds.), Learning the Literacy Practices of Graduate School: Insiders' Reflections on Academic Enculturation, Ann Arbor: University of Michigan Press, pp. 46-57.

Light, R.W. (2015), "Research: Why and how to write a paper?", Revista Clinica Espanola, Elsevier España, S.L.U., Vol. 215 No. 7, pp. 401-404.

Obuku, E.A., Lavis, J.N., Kinengyere, A., Ssenono, R., Ocan, M., Mafigiri, D.K., Ssengooba, F., et al. (2018), "A systematic review on academic research productivity of postgraduate students in low- and middle-income countries", Health Research Policy and Systems, Health Research Policy and Systems, Vol. 16 No. 1, pp. 1-8.

Rickard, C.M., McGrail, M.R., Jones, R., O’Meara, P., Robinson, A., Burley, M. and Ray-Barruel, G. (2009), "Supporting academic publication: Evaluation of a writing course combined with writers' support group", Nurse Education Today, Elsevier Ltd, Vol. 29 No. 5, pp. 516-521.

De Rond, M. and Miller, A.N. (2005), "Publish or perish bane or boon of academic life?", Journal of Management Inquiry, Vol. 14, pp. 321-329.

Shaw, P. (1991), "Science research students' composing processes", English for Specific Purposes, Vol. 10 No. 3, pp. 189-206.

Skelton, J. (1994), "Analysis of the structure of original research papers: an aid to writing original papers for publication", British Journal of General Practice, Vol. 4 No. October, pp. 455-459.

Sommers, N. and Saltz, L. (2004), "The novice as expert: Writing the freshman 
year", College Composition and Communication, Vol. 56 No. 1, pp. 124-129. Thrower, P. (2012), "Eight reasons I rejected your article", Elsevier, available at: https://www.elsevier.com/connect/8-reasons-i-rejected-your-article (accessed 2 April 2019).

Timmons, S. and Park, J. (2008), "A qualitative study of the factors influencing the submission for publication of research undertaken by students", Nurse Education Today, Vol. 28 No. 6, pp. 744-750.

Vintzileos, A.M. and Ananth, C.V. (2010), "How to write and publish an original research article", Am J Obstet Gynecol, Vol. 202 No. 344, pp. 1-6.

Ware, M. (2016), Publishing Research Consortium Peer Review Survey 2015. Wilson, J. (2012), Peer Review: The Nuts and Bolts. A Guide for Early Career Researchers, London, available at: https://senseaboutscience.org/wpcontent/uploads/2016/09/peer-review-the-nuts-and-bolts.pdf. 


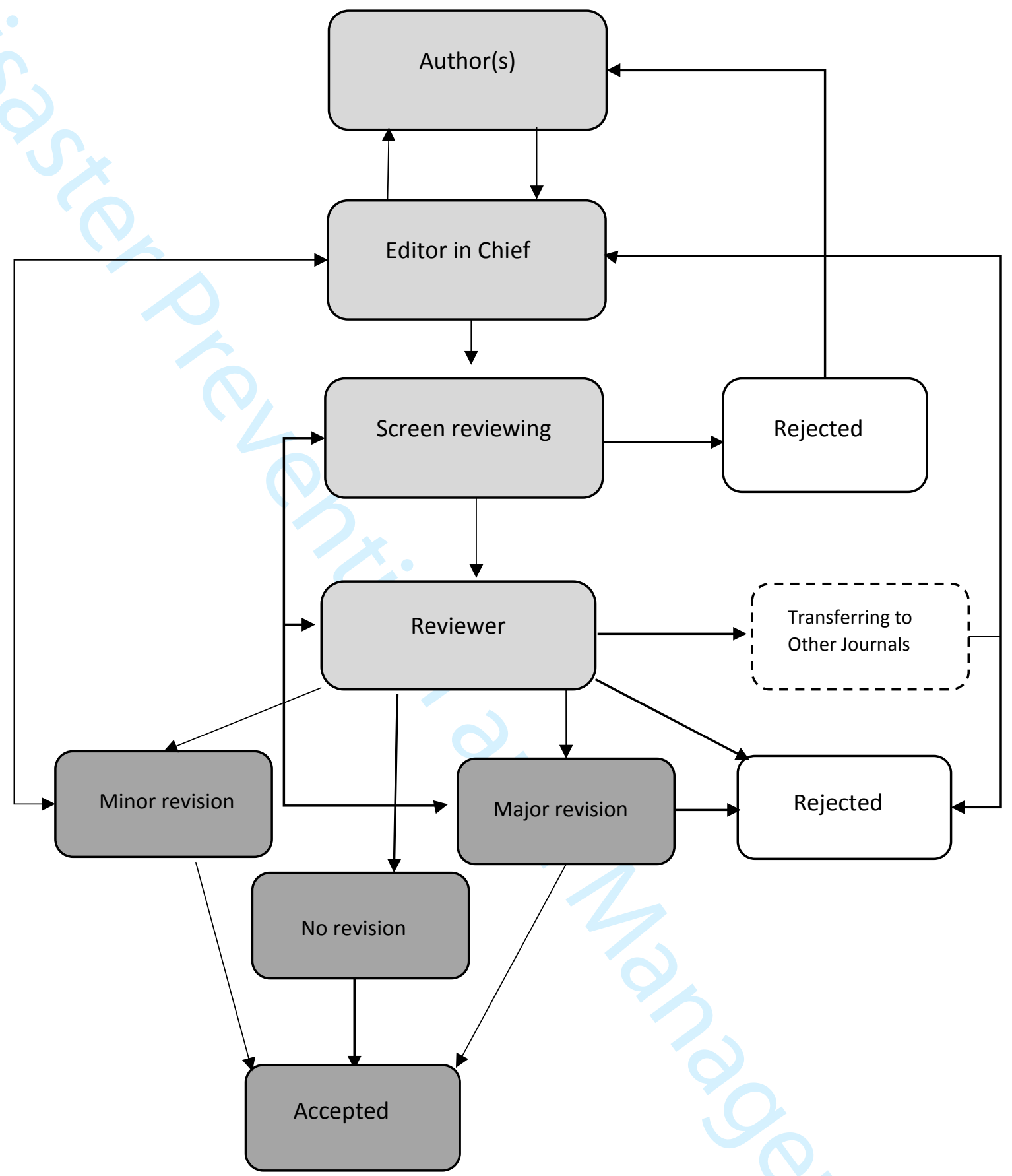




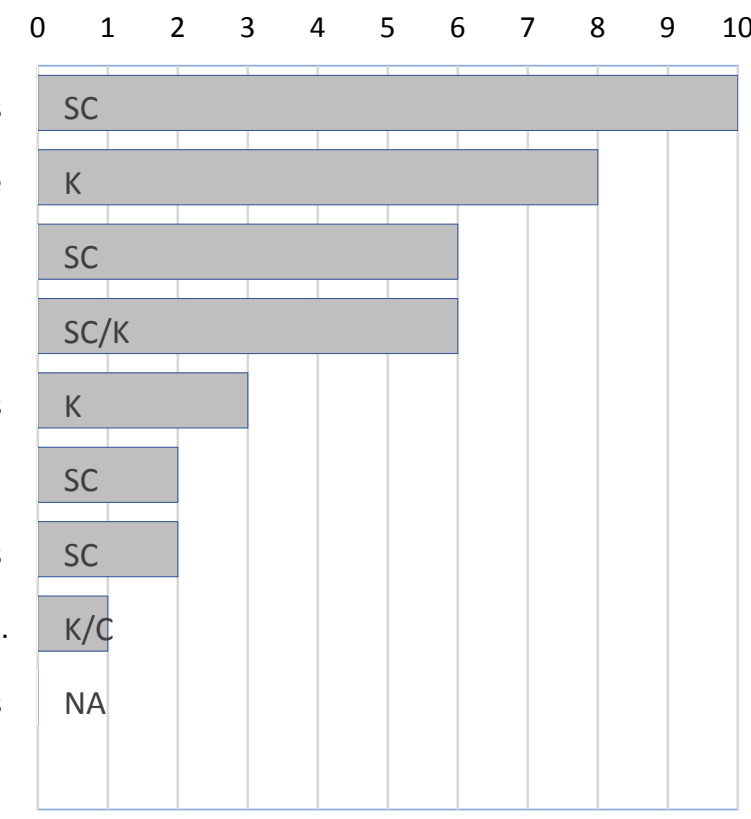

Notion that journal papers carry more weight than articles

$$
\begin{aligned}
& \text { Fear of the writing/rewriting process } \\
& \text { Knowing the relevant literature } \\
& \text { Going through the 'glass-wall' }
\end{aligned}
$$

Making a non-innovative contribution

Finding the most suitable journal for the topic/research goals

Dealing with paper rejection

Unknown/elusive goalposts

Additional...

$\square$ Challenges for novice researchers

Key: SC=Self Confidence; $\mathrm{K}=$ Knowledge; $\mathrm{C}=$ Communication

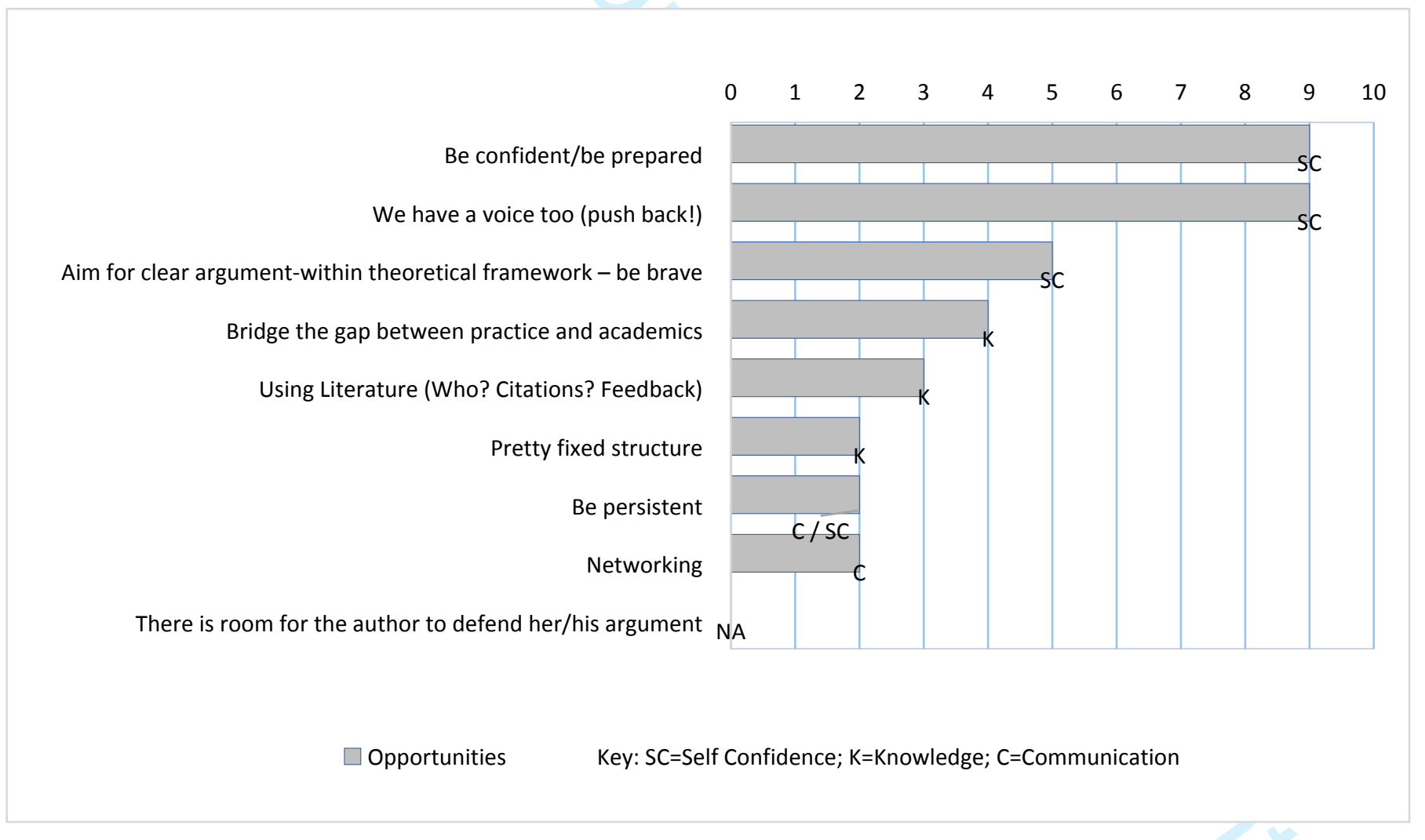


\begin{tabular}{|l|}
\hline Fear of the writing/rewriting proc \\
\hline Knowing the relevant literature \\
\hline Going through the 'glass-wall' \\
\hline Making a non-innovative contrib \\
\hline
\end{tabular}

Finding the most suitable journa

Dealing with paper rejection

Unknown/elusive goalposts

Additional reading to identify a jc theoretical/methodological

Notion that journal papers carry
Fear of the writing/rewriting $\mathrm{pr}$

Knowing the relevant literatı

Going through the 'glass-we

Making a non-innovative contrik

Finding the most suitable journal for the top

Dealing with paper rejectio

Unknown/elusive goalpost!

Additional reading to identify a journe theoretical/methodologica

Notion that journal papers carry more wei!

$\square$ Challenges for novice $r$ 
ocess

$\begin{array}{lllllllll}0 & 1 & 2 & 3 & 4 & 5 & 6 & 7 & 8\end{array}$

SC

ure $\quad \mathrm{K}$

all' $\quad$ SC

bution SC/K

)ic/research goals

In

SC

$\mathrm{S}$

SC

al's/editor's

I

\section{$\mathrm{K} / \mathrm{C}$}

ght than articles
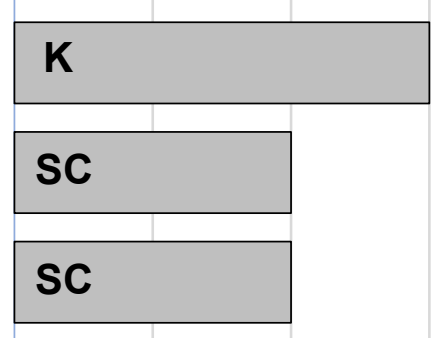

NA

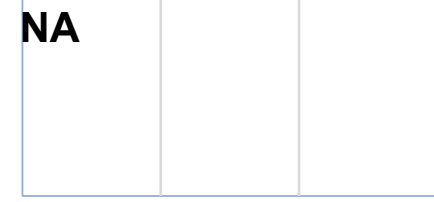

-esearchers

Key: SC=Self Confidence; K=Knowledge; C=Communicati 


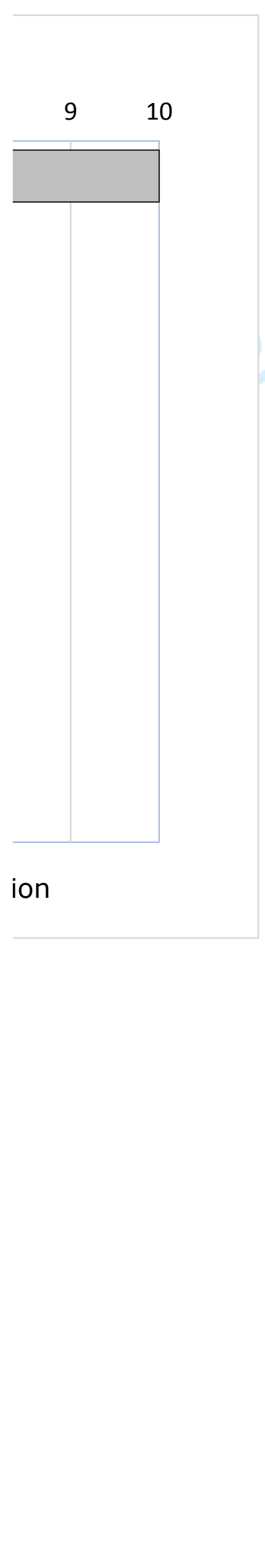




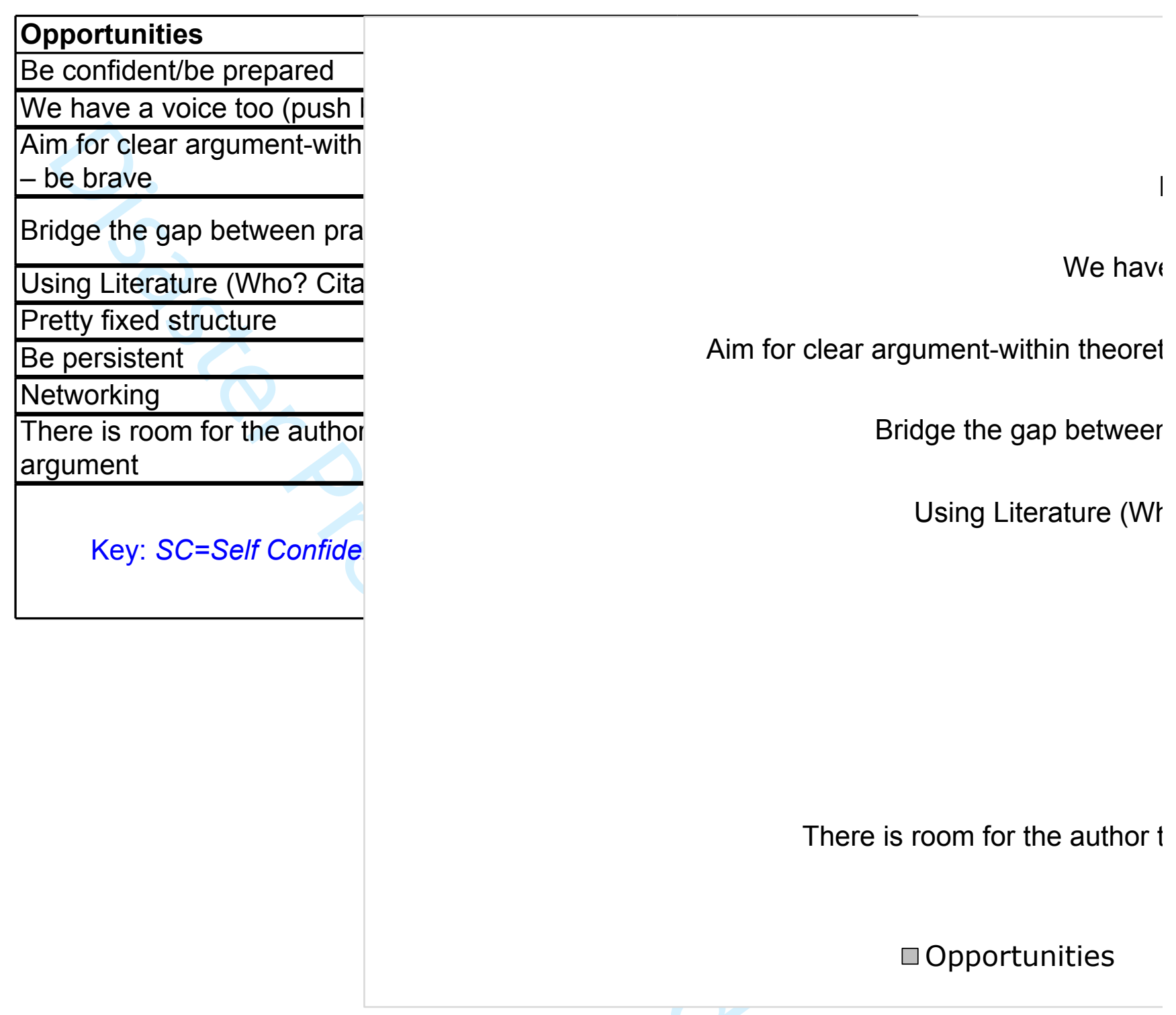




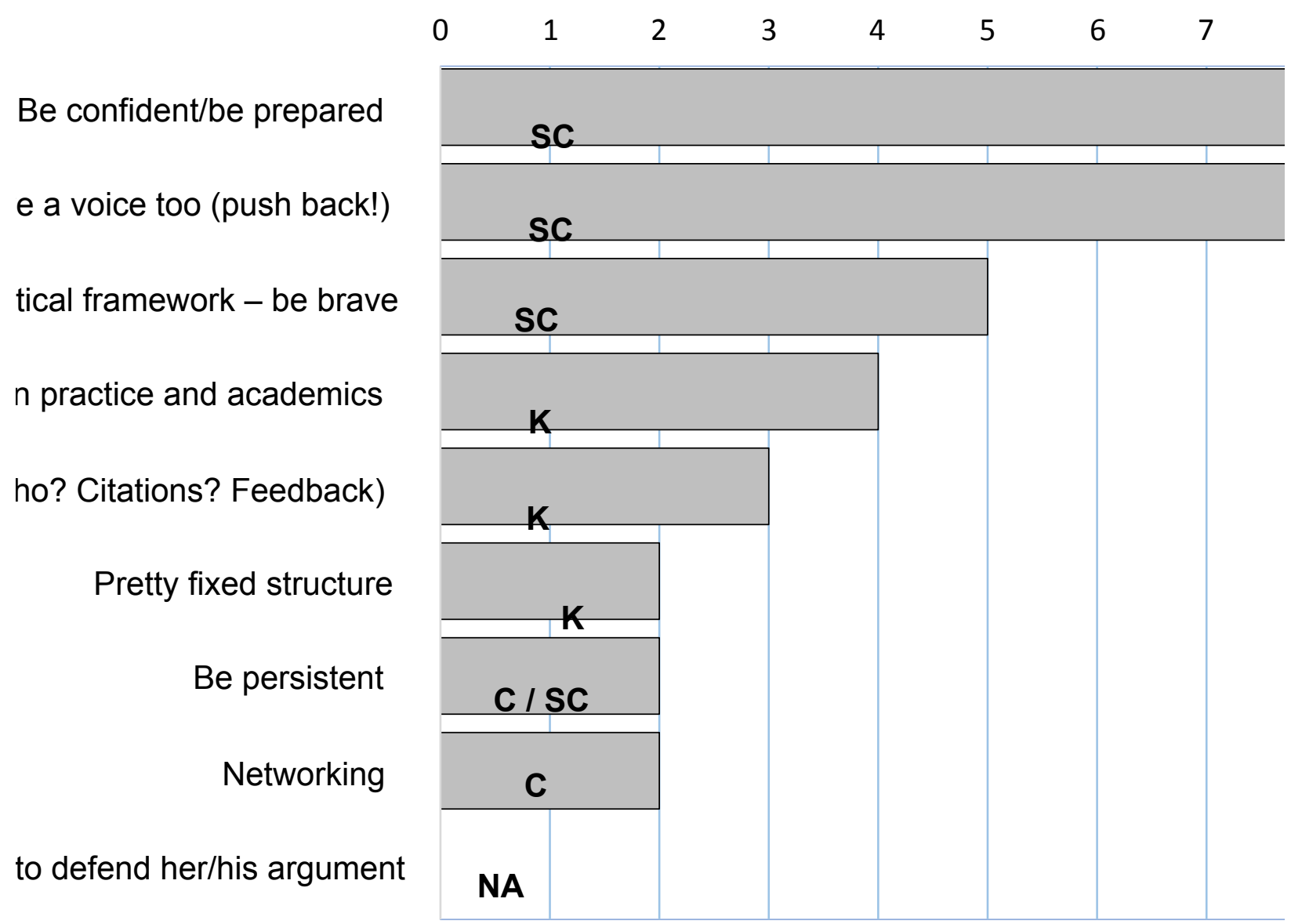

Key: SC=Self Confidence; $\mathrm{K}=$ Knowledge; $\mathrm{C}=$ Communication 


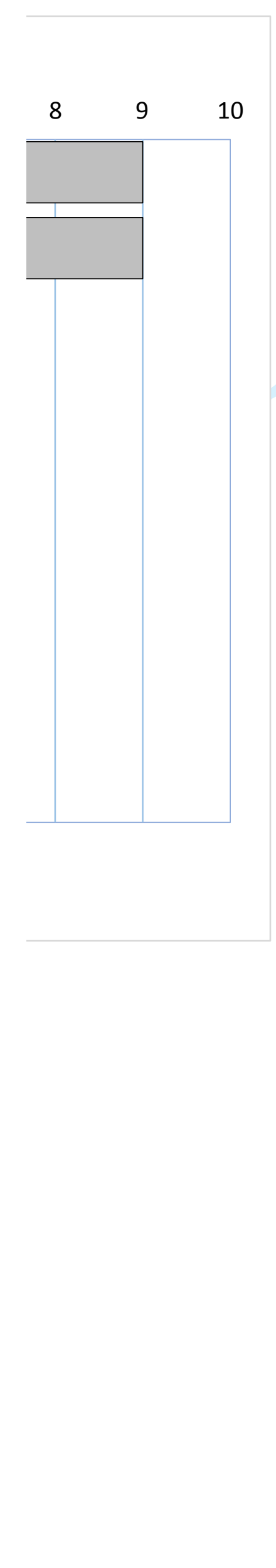

